\title{
Friedrich Meinecke's Interpretation of the Age of German Liberation
}

BY PETER PARET

Friedrich Meinecke's Age of German Liberation is one of relatively few works in the literature to focus directly and exclusively on German history from the French Revolution to Waterloo. Far more common are books that discuss these years as part of a longer sequence or analyze them through the lives of significant contemporaries. Despite their titles, such classic interpretations as Ranke's Hardenberg, Lehmann's Scharnhorst, or Ritter's Stein are general histories; but they are organized around a man, not the period. Even Meinecke, some years before he published Das Zeitalter der deutschen Erhebung, wrote a general history from the point of view of a particular life. His two-volume study of Hermann von Boyen, the originator of universal conscription in Prussia, is much more than a biography. But the extensive discussions of politics, of social and administrative change, of campaigns and diplomatic negotiations, are tied to an account of one man's development, successes and failures. It is as though works with such titles as Robespierre and the State or Carnot and the Emergence of Modern France constituted our major interpretations of the French Revolution.

Reasons for this difference in the treatment of crucial and nearly simultaneous segments of the French and the German past are not hard to find. One cause may be the bourgeois, idealistic character of much of German historical writing, which minimizes the determinative influence of social and economic factors, and instead emphasizes ideas, the individual, and the role of such generalities 
as the state or nation, which are interpreted as possessing a life of their own. I shall return to these objections, which have been raised repeatedly against Meinecke's work. It makes better sense, however, to seek the reasons for dissimilarities in approach to the French Revolution and to German reform not in historiography but in specific differences between the events themselves. The French Revolution occurred in a unified nation. German reactions to the Revolution were fragmented among dozens of political entities; indeed, achieving greater security through a measure of collaboration of autonomous and semi-autonomous German states quickly became one of the challenges of the time. The political fate of the German states in the Revolutionary and Napoleonic era varied from conquest and dissolution to growth under French patronage, and the character of modernization in those states that survived varied as greatly. To overcome the problems posed by this diversity Meinecke rests his interpretation on two collective elements-the force of German cultural development, which, he argues, combined with the power and energy of the Prussian monarchy to create a new political situation in Germany, the precondition for subsequent unification-but he does not fully succeed. His analyses of German culture necessarily encompass all of Germany; his treatment of German social and political change concentrates on one state: Prussia. To this day the political fragmentation of Germany before 1871 presents analytic difficulties to the historian. Even if he concentrates on social and economic rather than on political topics he may find his interpretation warped by the centrifugal force of interactions between a divided people and its many governments.

The absence of revolutionary change in Germany between 1789 and Napoleon's decline adds to the historian's difficulties in treating these years as a distinct period. All forces of continuity notwithstanding, the Revolution marked a deep incision in the history of France. Germany, by contrast, not only lacked political unity, but the adjustments that were undertaken by her many governments were tentative and gradual rather than radical. Unlike the changes that reconstituted French society, they were also partly defensive. They responded not only to the needs for modernization of German society, but at least as much to the needs for warding off French aggression, which for two decades proved to be invincible. The most symbolic and overtly dramatic incidents in German history between 
1789 and 1815 were totally unlike the fall of the Bastille, the Tennis Court oath, the execution of Louis XVI, Thermidor, Brumaire, the coronation of Napoleon-they were episodes in the continuing struggle against a foreign power: the cannonade of Valmy, the defeats of Jena and Auerstedt, the occupation of Berlin and Vienna, the victories of Leipzig and Waterloo. In France, too, change was prepared by earlier conditions and even emerged directly from them; but the survival of Germany's old elites, and the moderate nature of her political innovations, favored a view of these years of German history that emphasized continuity and organic development.

Finally, many historians would regard the years of reform and liberation as a failure. That might also be said of the French Revolution, which led to personal despotism, caused the death of hundreds of thousands in two decades of warfare, and transmitted severe social and ideological antagonisms to later generations. Nevertheless, the Revolution fully emancipated the French bourgeoisie, continued the country's administrative centralization, and asserted individual and national ideals that retain their potency to this day, and not only in France. The Revolution was international as well as national in scope, the outcome of centuries of European intellectual and social development. By comparison German achievements seem tame, or at least parochial. In the beginning, certainly, they were more a reaction to the Revolution than an expression of universal concerns-a difference probably not unrelated to the difference between a consolidated France and a fragmented Germany. Helped by their Russian and British allies, the German states destroyed French dominance over Central Europe; but they could not find an adequate political solution for the area. In the international community Germany remained something of a power vacuum, weakened by disunity and the rivalry of her two strongest states; while in internal affairs the signs of political activity that had emerged here and there were blotted out or circumscribed. It was to be one of the decisive factors of modern history that at the turn of the century the German bourgeoisie was still far weaker in size and economically than the French. The promise of greater participation in political life that had been held out to this minority was pushed aside after 1815 by a new bureaucratic absolutism, far less suited to a time of beginning industrialization and rapid population growth than it had been to the conditions of 
fifty years before. A sense of the disastrous effects that this stunted development was to have on Germany and Europe underlies one of the few books devoted specifically to the period, Walter Simon's The Failure of the Prussian Reform Movement. But on the whole, the disappointing, even ominous outcome of this phase of the German past appears to have given historians still another reason for preferring the larger view rather than focus exclusively on the period.

When Meinecke wrote the Age of German Liberation in the summer of 1905 this failure was not yet apparent to him. He regarded the years between the 1790's and 1815, which greatly simplified the political map of Central Europe, as a necessary preliminary to national unification-which they proved to be, although in the Napoleonic era a united Germany was neither possible nor generally desired-and he did not doubt that the German empire as it finally evolved was as historically justified and as permanent a political entity as were France, the United Kingdom, or Italy. That is not to say that he was unconcerned about some defects of the new Reich. He welcomed German unification under Prussian leadership, he accepted the institution of the empire as a realistic solution to the age-old problem of the multiplicity of German states; but he opposed the continuing hold of the old elites on much of public life, and advocated the strengthening of representative institutions in Prussia as well as on the national level. $\mathrm{He}$ wrote the Age of German Liberation both to celebrate the achievements of the early years of the 19th century, and to warn that what he regarded as basic to that achievement-the "alliance" between the Prussian state and the ideas, ideals, and creativity of educated, that is, middle-class Germany-still awaited full implementation. As the introductory chapter of the Age of German Liberation indicates, he recognized that the cultural values of the generations of Kant and Goethe, to which he attributed not only spiritual but also political power, were no longer genuinely significant to most modern Germans. But he believed that the middle class retained a stronger sense of them than did any other segment of German society. A revitalized, politically more effective bourgeoisie, a government prepared to adjust to modern conditions, an extension of social justice and humanistically inspired education to the 
industrial and agricultural proletariat-these seemed to him the still unfulfilled promises of the earlier age. It was only in the framework of a strong state, he believed, that they could be brought to reality.

Readers today may be disturbed by the frank patriotism sounded in some of Meinecke's passages. At the time he wrote, however, few historians whatever their nationality seriously questioned the necessity of the great political systems that had coalesced since the Renaissance. French and English as well as German scholars, though profoundly conscious of their Western heritage, which their own research was probing more deeply every year, could be guilty of cultural and ethnic judgments that are astonishing in their smugness and even brutality. Patriotism of an assertive, increasingly irritated kind was a general European phenomenon, which played a part in the coming of the first World War, but in the Age of German Liberation it is at most of marginal importance. The satisfaction that Meinecke felt in the establishment of the second German Reich may be alien to us; but it does nothing to distort his analyses of the development of Prussia before 1789, her reconstitution in the crucible of the Revolution and the Napoleonic era, and the beginning politization of modern German culture.

Another element in the Age of German Liberation may be of greater significance. Although the precise differentiation between closely related phenomena was basic to all of Meinecke's work in the history of ideas, in the present book he resorts to such collective generalizations as "spirit," "nation," and "state." In some respects these generalizations are no more than necessary shorthand in a treatment that is both brief and aims to be comprehensive, and the terms are always employed with an awareness of the variety of phenomena underlying them. Nevertheless they can be dangerous analytic devices because they posit what may be called an operational unity of attitude, intent, or action. Of the three, "nation" and "spirit" play a relatively unambiguous role. Meinecke uses "nation" in something akin to its original apolitical or prepolitical sense of people living in the same geographic area, sharing historical traditions and cultural attributes. Occasionally the term is given its narrow 18th-century meaning of cultural and social elite, more often it stands for the German people as a whole; and the growing 
link between the former and the latter is one of the main themes of the work. "Spirit" usually refers to achievements of German intellectuals and artists that acquire some permanence, that is, a degree of general acceptance, and that despite individual differences evince a basic affinity-an affinity that increases, Meinecke suggests, the more clearly their work expresses the characteristics of the nation.

That these characteristics can be given different form, that they may even be contradictory, Meinecke reveals with admirable clarity in the book's third chapter, "German Cultural Life and the Prussian State before 1806." Indeed, no one has traced the movement of ideas and attitudes from cosmopolitanism to nationalism with deeper insight than he. But in a work as brief as the Age of German Liberation some simplification is inevitable. The alternative was to exclude intellectual and cultural factors altogether. That, however, would have resulted in a totally false picture because the leaders of the Prussian reform movement were influenced by the intellectual currents of the age and contributed to them actively as writers, theorists, and even philosophers.

Meinecke's use of the word "state" may present greater difficulties. It was an important advance in historical understanding when toward the end of the Enlightenment men began to regard the European states as political organisms that changed over time in much the same way human beings develop without losing their basic physical and psychological features. This conceptualization, arising from a new sensitivity for the numerous indications of continuity in the past, but also from political theories that had little to do with historical evidence, helped make possible a less abstract, more specific approach to history. Men learned to try to interpret the past more in its own terms than in theirs. But this remarkable declaration of intellectual independence from the pressures of the present was accompanied by an attitudinal danger. The state seen as a historical personality comes to assume a life of its own. From this idea it is only a short step to attributing characteristics and motives to the state that are separate from the characteristics and motives of real people. It is then easily forgotten that at each stage of its existence the state like any other institution is an assemblage of men. Obviously people are influenced by the past and present cir- 
cumstances of their institution, but it is man who acts, not the state.

Meinecke was far too knowledgeable and intelligent a historian to romanticize the state, and to ignore the impact of individual and class interests on its policies. He never regarded the personification of the state as implying the abdication of personal responsibility. But his analysis of Germany at the beginning of the 19th century assigns great significance to "those supra-individual forces that informed custom and tradition, that lived in the spirit of the people and nation as a whole." He rejected the thesis of the origin of European states developed by the doctrine of natural law, which "argued that the state was created by a contract between men, in other words through a decision of the will guided by reason." Instead he calls our attention to the "strange mixture of light and dark [that] makes up even the individual's ethical and intellectual powers"-with the implication that this mixture is still more strongly present in the state-and emphasizes historical forces "over and beyond the world of conscious action" that direct the paths of men. The conflict between state and individual is stressed throughout the Age of German Liberation, but some readers may feel that at times Meinecke assigns too great an authority to the state as a historical personality, a carrier of supra-individual forces.

Before and during the first World War this conception of the state, and especially the Prussian state, was rejected by such Marxist historians as Franz Mehring, although Mehring directed his critique not at Meinecke's work, but at the writings of Meinecke's colleague and friend Otto Hintze.' After the war Mehring's criticism was taken up and turned specifically against Meinecke by one of Meinecke's own students, Eckart Kehr. In particular, Mehring and Kehr objected to the absence in studies of the Prussian reform era of a systematic analysis of economic and social factors within the framework of class conflict, which, they asserted, would have shown that the Prussian monarchy, willingly or unwillingly, was subservient to narrow class interests, and that many of the reformers themselves were by no means political idealists.

1. Franz Mehring's review essay of Otto Hintze's history of Prussia, Die Hohenzollern und ihr Werk, first appeared in installments in 1915 and 1916. It was reprinted in Mehring's Gesammelte Schriften und Aufsätze, iii, Berlin, 1930, pp. 55-135. 
Kehr went further and interpreted Meinecke's emphasis on the power of ideas in history as an expression of the continuing political impotence of the German bourgeoisie. At the beginning of this century, he wrote in 1933, the German middle class had the choice of accepting the politics of imperialism or of joining the Social Democrats in opposition. Those unwilling to do either sought escape in a resigned, estheticizing view of the world. This attitude $\mathrm{Kehr}$ regarded as the root of Meinecke's method of studying the history of ideas and of its popularity, which made Meinecke the most influential German historian of his generation. By interpreting political and social developments through the vehicle of intellectual history, Meinecke, according to Kehr, had shown

the intellectually disoriented bourgeoisie a way out of its difficulties. In the long run, it is a dead end. But temporarily those who enter it are strengthened and exalted. They feel as if they are on a high mountain from which they look down into a squalid valley where the mob, struggling for its daily bread, is penned in by a narrow horizon and cannot see the light beyond. The superiority complex of the mountain climber is highly developed in the intellectual historian . . . But is this feeling of superiority well-founded? The genesis of the German history of ideas amply demonstrates that it has not concerned itself with things that have had great and direct practical implications. It shies away from ideas that have revolutionized or attempted to revolutionize the world. Democratic ideas in America or France, Socialist ideas in Germany, Bolshevist ideas in Russia are all taboo, for they could only be treated by someone who has formed his own opinion about the social and political situation and has envisaged revolution and collapse in his own country. The historians of ideas are inclined to view such revolutions as repellent, because they force them to make hard choices for or against. Even if they are republicans and democrats, they are politically conservative. They take no interest in workers or employees. The problems of the latter are confined to the day-to-day struggle and are irrelevant at the lofty levels over which the historian of ideas holds sway. ${ }^{2}$

Only a writer committed to the proposition that in the 20th century historical studies were dishonest or antiquated unless they served the cause of socialism could have failed to mention that two of Meinecke's most important books, Cosmopolitanism and the

2. Eckart Kehr, "Modern German Historians," in the collection of his essays, Economic Interest, Militarism, and Foreign Policy: Essays on German History, edited by Gordon Craig, Berkeley and Los Angeles: University of California Press, 1977, pp. 181-182. 
National State and Machiavellism, dealt precisely with ideas that had changed the world; but these were ideas that Kehr hated, particularly at a time when Germany was descending into modern barbarism. Actually Kehr was not so much hostile as indifferent to the history of ideas, which he appears to have thought of as unimportant in itself but overly seductive to scholars who might more usefully have explored the economic and social motives of political decisions. It was Hitler's rise to power with the support or acquiescence of many German intellectuals that led Kehr in the days of the Reichstag fire to reject the history of ideas with a vehemence not otherwise found in his writings. Nevertheless his criticism impressed, and still impresses, some historians, who go beyond Kehr in dismissing ideas as nothing but superstructures of the social and economic substructure, a substructure they regard not only as the ultimately significant subject for the historian, but which they interpret in accord with their political convictions and their sense of present and future political needs.

The weakness of this kind of history-its ultimate degeneration into ideology and party slogans-is revealed by parallels to Kehr's attack on Meinecke in the writings of a scholar who in every respect was Kehr's inferior but who held essentially the same position on the issue that matters here, the prominent National Socialist historian Walter Frank. After Frank in 1936 had forced Meinecke to resign from the editorship of Germany's leading historical journal, the Historische Zeitschrift, he continued to denounce his works as expressions of a decayed social order. "Capitalist bourgeois society," he wrote, echoing Kehr, "had developed a capitalist bourgeois science of history." Meinecke's analyses emphasized ideas rather than power because Meinecke did not understand power, which he misinterpreted as a combination of ethical and immoral or amoral qualities. On the contrary, power in the right cause could only be good. "A Hamlet-like pallor hung over this declining [bourgeois] culture," whose place had now been taken, Frank declared, by a society and a science of history invigorated by the creed of Nationalsocialism. ${ }^{3}$

Their rhetorical excesses notwithstanding, these polemics contain

3. Walter Frank, "Die deutschen Geisteswissenschaften im Kriege," Historische Zeitschrift, CLXIII, No. 1 (1941), pp. 7-8. 
some valid points. Any appraisal of a historian's works can appropriately inquire into their author's social and cultural roots. Meinecke himself acknowledged that growing up in the tradition of Prussian neo-humanism was not only a source of strength but also limited his outlook. Kehr was correct when he noted that ultimately Meinecke's sympathies rested with intellectual elites, and Frank rightly suspected that Meinecke's patriotism would not embrace the destruction of Western culture for the sake of German hegemony. The dream of pure, objective history, scorned for different reasons by Kehr and Frank, is indeed a dream. Like every historian, Meinecke had affinities, in which political convictions played a part, that helped determine his choice of topics for research, his selection of sources, and his interpretations. But the impossibility of complete detachment has never meant that the only alternative for history is complete politization.

It remains the most valid criticism of Meinecke's work that he did not balance his analyses of ideas with equally penetrating explorations of social and economic factors, and, further, that, in Felix Gilbert's words, he did not "pursue the study of intellectual trends to an analysis of the social forces which they represented." 4 His work, like that of every historian, investigates only some, not all, facets of his topic. But that is not to say that Meinecke disregarded the social and economic spheres. The Age of German Liberation contains precise analyses of social conditions, and Meinecke's evaluation of the course of urban and agrarian reform, far from perfunctory, is that of a scholar fully engaged in his task. Such recent critical studies as Hajo Holborn's History of Modern Germany closely follow the account of the liberation of the peasants and the reorganization of municipal government in the Age of German Liberation. ${ }^{5}$ The modern monographic literature on specific aspects of Prussian social and economic history does not so much contradict as complement and expand on Meinecke's concise treatment. ${ }^{6}$

4. Felix Gilbert in his Introduction to the American edition of Meinecke's Cosmopolitanism and the National State, Princeton, 1970, p. xiv.

5. Compare, for instance, pp. 78-86 of the present work with Hajo Holborn, $A$ History of Modern Germany, ii. New York, 1964, pp. 403-410.

6. Even Kehr's interpretations of the period, though stressing social and economic motives, reveal striking agreements with Meinecke. To give just one example, his 
If the Age of German Liberation is not solely concerned with abstractions it nevertheless is very much the work of an intellectual historian, who applies his view of the nature and role of ideas to an exceptionally eventful period in the political and military history of Europe. The book's treatment of ideas revolves around three poles. It traces the growth of ideas-the ebb and flow of Fichte's patriotism, for instance, or the slow emergence of a militarybureaucratic concept of the Prussian state. Ideas, however, are interpreted not only as steps in the intellectual development of an individual, a group, or nation; they are also seen as phenomena that deserve to be studied for their own sake and in their own terms. Finally, the book examines ideas in their cultural as well as socioeconomic context. The Age of German Liberation takes ideas seriously -in themselves, as expressions of a continuing process of intellectual development, and as forces for political, social, and economic change.

This many-faceted approach is developed in terms that despite the outdated elements I noted earlier have lost none of their logic and interpretive force. An example is the genetic rather than static method of intellectual history, employed both in the interpretation of individual intellectual systems and of the development of broadly held beliefs. Another is Meinecke's use from the opening paragraph on of the comparative method, which opposes and contrasts individuals, societies, and even historical periods to define specific German conditions more sharply and fit the German experience into the context of world history. Yet another is Meinecke's rejection of closed historical categories in favor of a comprehensive analysis that tries to demonstrate the interdependence and interaction of all aspects of the period-political, military, economic, and cultural.

The integrative character of Meinecke's analysis benefited from the position the Age of German Liberation assumes in his oeuvre. He wrote the book after twenty years of archival research in Prussian administrative and political history, and just before launching on his great innovative studies in the history of ideas, for which, in some

characterization of Stein in his essay "The Genesis of the Prussian Bureaucracy and The Rechtsstaat," Kehr, p. 146, reads like a paraphrase of the analysis of Stein in the Age of German Liberation. 
Meinecke's Interpretation of the Age of Liberation

respects, it is a preliminary sketch. The Age of German Liberation bridges the two major phases of Meinecke's scholarly life, and contains elements of both, just as it links two major forces-state power and cultural and intellectual development-in Germany at the beginning of the 19th century. The little book thus offers both an interpretation of a crucial period of Germany's past and an introduction to the thought and method of one of her great historians. 